\title{
Contribution of transcranial oscillatory stimulation to research on neural networks: an emphasis on hippocampo-neocortical rhythms
}

\author{
Lisa Marshall ${ }^{1,2 *}$ and Sonja Binder ${ }^{1}$ \\ ' Department of Neuroendocrinology, University of Lübeck, Lübeck, Germany \\ ${ }^{2}$ Graduate School for Computing in Medicine and Life Sciences, University of Lübeck, Lübeck, Germany
}

\section{Edited by:}

Shennan A. Weiss, Columbia

University, USA

\section{Reviewed by:}

Christoph S. Herrmann, Carl von Ossietzky University, Germany

Lluís Fuentemilla, University of

Barcelona, Spain

Flavio Frohlich, University of North

Carolina - Chapel Hill, USA

\section{*Correspondence:}

Lisa Marshall, Department of

Neuroendocrinology, University of

Lübeck, Haus 50.1, Ratzeburger Allee

160, 23538 Lübeck, Germany

e-mail: marshall@kfg.uni-luebeck.de

\begin{abstract}
EEG rhythms reflect the synchronized activity of underlying biological neuronal network oscillations, and certain predominant frequencies are typically linked to certain behavioral states. For instance, slow wave activity characterized by sleep slow oscillation (SO) emerges normally during slow-wave sleep (SWS). In this mini-review we will first give a background leading up to the present day association between specific oscillations and their functional relevance for learning and memory consolidation. Following, some principles on oscillatory activity are summarized and finally results of studies employing slowly oscillating transcranial electric stimulation are given. We underscore that oscillatory transcranial electric stimulation presents a tool to study principles of cortical network function.
\end{abstract}

Keywords: tACS, tDCS, sleep, memory, learning, brain rhythms
The concept that oscillatory brain electric activity-as measured in the EEG or as local field potentials-is more than just an epiphenomenon and can directly impact biological neuronal network activity has existed for some time (Buser and Rougeul-Buser, 1995; Jefferys, 1995; Vigmond et al., 1997). An upsurge of interest in modulating oscillatory activity by applying oscillatory weak electric currents results on the one hand from the recent accumulation of studies on the functional efficiency of applied oscillatory weak electric fields and currents in modulating EEG, local field potentials and neuronal firing rates (reviewed in Weiss and Faber, 2010; Herrmann et al., 2013). On the other hand, the interest in neuronal oscillations and their behavioral relevance has become of increasing interest in the last decade, resulting mainly from studies indicating that precise timing of neuronal activity within oscillatory neuronal networks is essential for information coding and that network oscillations can be a mode of communication between distinct neuronal groups and across brain structures (e.g., Buzsáki and Draguhn, 2004; Fujisawa and Buzsáki, 2011; Hyman et al., 2011; Maris et al., 2011). The study on effects of (transcranially) applied weak oscillatory electric currents is therefore of at least three-fold importance: firstly, as a non-invasive tool for modulating endogenous bioelectric activity, and thus with therapeutic potential; secondly, for investigating the dependence of behavior on brain oscillatory activity; and thirdly, as a tool to study principles of cortical network function.

This mini-review focuses on effects of oscillatory transcranial electric stimulation in particular for learning and for the consolidation of hippocampus-dependent memory. First, an introduction leading up to present concepts and questions on hippocampus-dependent memory consolidation is given.
Then we discuss correlates of brain electric activity, cellular and network dynamics. In the second part, features of neuronal and network activity are pointed out which we find relevant to consider when attempting to employ oscillatory stimulation as a tool to study cortical network function.

An association between the hippocampus and memory was established from findings on memory performance in relation to temporal lobe lesions in monkeys (Brown and Schäfer, 1888), hippocampal atrophy (Bechterew, 1900), reports on memory flash backs with hippocampal stimulation (Penfield, 1974), and from reports in the mid-twentieth century differentiating anterograde and retrograde amnesia following well-defined hippocampal lesions as in the case of H.M., the probably most well-known amnestic patient in the history of neuroscientific memory research (Scoville and Milner, 1957). Concepts for neurophysiological memory trace formation, two stage models of memory stage formation, emerged, within which information is transferred to the long term memory store, the neocortex, via hippocampo-cortico connections during the hippocampal sharp wave ripple (SWR) events of slow wave sleep (SWS; Marr, 1970, 1971; Buzsáki, 1989). Later developments of the two stage model aimed to integrate the mechanism of long term potentiation (LTP) in the normal brain (Buzsáki, 1989). It suggested that neuronal firing patterns during hippocampal sharp waves must be the most favorable conditions for enhancement of synaptic plasticity, as SWRs produce powerful synchronization within the pathways connecting the hippocampus to the neocortex (Chrobak and Buzsáki, 1996). The model furthermore incorporated the relevance of behavior and state-dependent changes for defining neuronal patterns (Buzsáki et al., 1987; Buzsáki, 1989). 
This concept in which hippocampal theta activity during exploratory behavior in rats supported memory trace formation led to renewed interest in hippocampal place cells (O'Keefe and Dostrovsky, 1971; O'Keefe and Recce, 1993). Subsequent discovery of spatially selective firing of hippocampal place cells in regard to tasks involving spatial memory was the impetus for many investigations on post-experience hippocampal spatiotemporal activity patterns, i.e., reactivation, mostly during SWS (Pavlides and Winson, 1989; Wilson and McNaughton, 1994; Skaggs and McNaughton, 1996; Nadasdy et al., 1999; Hirase et al., 2001; Lee and Wilson, 2002), but also during rapid eye-movement (REM) sleep (Louie and Wilson, 2001); for comprehensive reviews see, Buhry et al. (2011) and Sadowski et al. (2011). Experience-dependent reactivation in sleep was also shown in humans (Rasch et al., 2007; Oudiette and Paller, 2013).

A hallmark of SWS is the endogenous cortical slow oscillations (SO), which coordinates not only thalamo-cortical sleep spindle activity, but also hippocampal SWRs (Timofeev and Steriade, 1996; Isomura et al., 2006; Mölle et al., 2006), slow field potentials with superimposed fast ripple oscillations closely associated with memory consolidation (Fogel and Smith, 2011; Girardeau and Zugaro, 2011). The sleep SO with its coordinating function plays a crucial role in sleep-dependent memory consolidation, specifically for cortico-hippocampal communication (Marshall and Born, 2007). A schematic depiction of these supposed mechanisms is given in Figure 1.

Outstanding experimental support at the level of cell-pairs for the relevance of SWRs for hippocampo-to-neocortical information transfer was given by Wierzynski et al. (2009). During
SWRs of SWS, but not during REM sleep, cell pairs showed strong correlations with firing of CA1 hippocampal cells preceding that of prefrontal cell. A functional synaptic connection between hippocampus and prefrontal cortex (PFC) has also been indicated by prefrontal phase locking to hippocampal units during hippocampal theta oscillations while performing a task (Siapas and Wilson, 1998; Hyman et al., 2005). Together these studies indicate nicely that the same neuromorphological structures and pathways are differentially activated dependent on global brain state, i.e., sleep or active task performance. Most importantly, temporally coordinated hippocampal and PFC activity has been most frequently characterized in association with population level activity (Siapas and Wilson, 1998; Sirota et al., 2003; Isomura et al., 2006; Mölle et al., 2006; Peyrache et al., 2011). Aside from being technically more easily obtained than paired single cell recordings, population activity can contain different and vastly more complex information than obtained from single cell recordings (Kopell et al., 2010; Wallace et al., 2011). Coherent firing patterns and enhanced synchronization of rodents' hippocampal and prefrontal activity has been associated with enhanced memory performance (Benchenane et al., 2010; Fell and Axmacher, 2011; Kim et al., 2011). For instance, Hyman et al. (2010) showed entrainment of medial PFC to the hippocampal theta rhythm correlated with successful performance in a working memory task. Based on these findings it has been suggested that oscillations regulate communication between the hippocampus and medial PFC (Benchenane et al., 2011; Colgin, 2013). However the rules underlying this oscillatory communication, in fact even the rules regarding the relationship of single cells to network activity as well

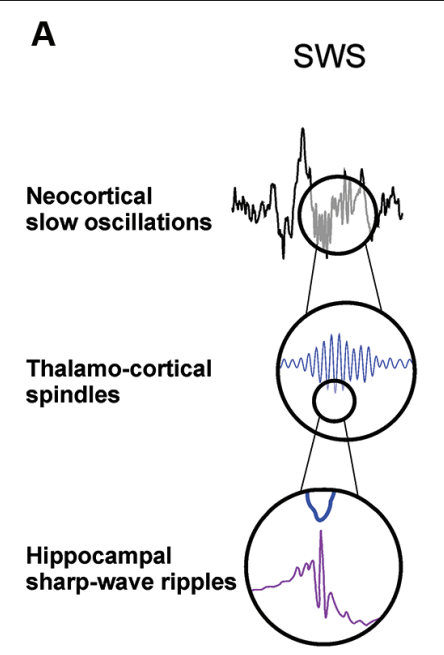

B
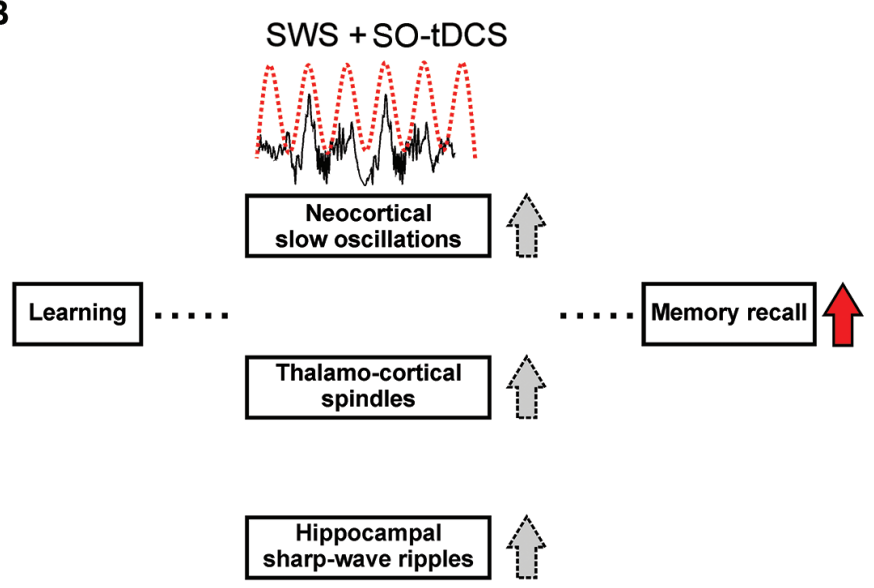

FIGURE 1 | Sleep-associated brain oscillations relevant for memory consolidation and supposed effects of SO-tDCS (slow oscillatory transcranial direct current stimulation). (A) Temporal relation of $\mathrm{SO}$, sleep spindles and hippocampal SWRs. Sleep spindles and hippocampal SWRs occur preferentially within the Up-state of the SO (Isomura et al., 2006; Mölle et al., 2009). SWRs are temporally coupled to spindles, with individual SWRs nesting into the troughs of spindles (Siapas and Wilson, 1998; Wierzynski et al., 2009; Clemens et al., 2011). Pre-sleep learning enhances activity of and coherence between these oscillations (Mölle et al., 2009), and it is assumed that the interplay of these oscillations subserve the communication between hippocampus and neocortex (Sirota et al., 2003) and therefore the transfer of hippocampus-dependent memory traces from the hippocampal short-term-store to the neocortical long-term store (for review see Marshall and Born, 2007). (B) SO-tDCS is assumed to enhance endogenous SO activity, and thus improve the consolidation of memory. It was shown that SO-tDCS enhances post-stimulation power of EEG SO and spindle activity as well as memory consolidation in a hippocampus-dependent task (Marshall et al., 2006). A simultaneous enhancement of these rhythms and SWRs during SO-tDCS yet needs to be shown. 
as the interplay between intrinsic properties of the neuron and its inputs, are matters of ongoing research (Akam and Kullmann, 2012).

In the following we point out some essential principles of brain rhythms which indicate how studies employing transcranial weak oscillatory currents can contribute to understanding cortical network function.

Single neurons involved in oscillatory activity do not necessarily fire once per cycle, nor even with the frequency of the network oscillation, but properties of neurons matter with regard to determining collective network synchrony (Jacobs et al., 2007; Csercsa et al., 2010; Wang, 2010). One intrinsic neuronal property relevant for cellular responsiveness and therefore ultimately influencing resultant network activity is preferred resonant frequency. At the single cell level, neuronal resonance typically requires a combination of active and passive properties of a neuron, i.e., passive membrane properties functioning as a low pass filter and voltage-gated active channels which give rise to high pass filtering (Hutcheon and Yarom, 2000; Wang, 2010; Yoshida et al., 2011). Pyramidal neurons in the neocortex can have two resonances which occur at different membrane potential levels (Hutcheon and Yarom, 2000) and neurons of different brain regions have been shown to phase-lock to oscillations at multiple frequencies (Jacobs et al., 2007). Supra- and subthreshold noise, in part arising from neuromodulatory activity, can furthermore significantly affect the interplay between intrinsic properties of the neuron, its inputs and oscillations at network level (Hutcheon and Yarom, 2000; Richardson et al., 2003; Jacobson et al., 2005; Giocomo and Hasselmo, 2007; Wang, 2010; Heys and Hasselmo, 2012).

At the network level, the application of weak oscillatory currents is most effective at the resonance frequency of the network, characterized by the presence of an Arnold's tongue (i.e., preferred enhancement occurs at this resonance frequency at weak amplitude of the applied current; Ali et al., 2013). Transcranial weak oscillatory currents most commonly induce enhanced EEG activity at the frequency of the applied current. This has been shown and modeled for currents applied at gamma (Strüber et al., 2013), mu/beta (Pogosyan et al., 2009), alpha (Zaehle et al., 2010; Neuling et al., 2012; Merlet et al., 2013), theta (Marshall et al., 2011) and SO's, the latter in human subjects (Marshall et al., 2006) as well as in animal and in slice experiments (Fröhlich and McCormick, 2010; Ozen et al., 2010). We will focus the below discussion on SO-tDCS, which refers to any stimulation of the same frequency as the endogenous sleep SO (ca. $0.75 \mathrm{~Hz}$ in humans), and has a direct current (DC) bias. Another term used so far is transcranial slow oscillation stimulation (tSOS). Precise stimulation parameters (amplitude, duration, shape of the periodic signal and on-/off-set of the oscillatory train) may however vary between experiments. Which effects most of these variables have are yet unclear (see e.g., Groppa et al., 2010, who compared effects of similarly parameterized constant and SO-tDCS).

The mechanisms and prerequisites responsible for resonant EEG activity induced by transcranial weak oscillatory stimulation are still in need of further research. While it is in line with theoretical concepts described above and in Figure 1 that SO-tDCS over the dorso-lateral PFC during SWS in humans enhanced EEG power both in the SO and spindle frequency ranges (Marshall et al., 2006), effects of SO-tDCS during waking are more difficult to reconcile. In waking SO-tDCS enhanced SO's locally as well as widespread theta activity $(4-8 \mathrm{~Hz})$, but not centro-parietal beta activity (Kirov et al., 2009). Was this theta enhancement, also shown to enhance learning, i.e., of functional relevance, only observed because theta was a predominant brain rhythm at this time? Or could EEG theta arise from interactions with specific properties of cellular resonance and/or recurrent network activity? Associations between slow wave and theta band activity exist at many levels, for instance theta nesting in delta activity (Laktos et al., 2005; Carracedo et al., 2013) and parallel modulations in ontogenetic development (Campbell and Feinberg, 2009). Furthermore, similar mechanisms, namely balanced recurrent excitatory and inhibitory activity, have been suggested to underlie the persistent activity during the SO UP state and working memory, the latter being characterized by theta oscillatory activity (McCormick et al., 2003; Reato et al., 2010). However, information on brain state-dependent network dynamics of the interaction between rhythms is still scarce.

The variability in results we and others have observed employing SO-tDCS (e.g., Eggert et al., 2013, who were unable to replicate the results of Marshall et al., 2006, in elderly subjects; Göder et al., 2013, who reported less forgetfulness in schizophrenic patients after stimulation) may in part be inherent to the system. For instance, two studies on SO-tDCS during sleep in healthy individuals showed different results regarding faster rhythms. SOtDCS during an afternoon nap did not modify spindle power, but did enhance wide-band beta activity as compared to sham (Antonenko et al., 2013). The nap-study differed however in behavioral and temporal parameters from the former, e.g., there was no pre-sleep learning and sleep occurred during a different time of day. Thus not only did experience-dependent features of the neuronal networks differ, but also circadian factors and sleep propensity (such as neuromodulators; Vittoz and Berridge, 2006; Morris et al., 2012; Schmitt et al., 2012). Considering transcranial weak oscillatory stimulation affects subthreshold activity (cp. Reato et al., 2013a, this issue), it is well conceivable that any of the above factors affected single cell and cortical network properties. By virtue of its primary effect on cortical networks we hypothesize that SO-tDCS modifies the efficiency of hippcampoto-neocortical activity.

Finally, up until now only rather short term effects have been considered, yet memory can improve across days with repeated learning. Constant tDCS has been shown to modify plasticity related products (Fritsch et al., 2010; Stagg and Nitsche, 2011). Long term modifications in oscillatory neuronal activity have to our knowledge only been reported up to $30 \mathrm{~min}$ in a statedependent manner for alpha-activity following transcranial alternating current stimulation (tACS) at individual alpha frequency following stimulation (Neuling et al., 2013), and a putative role of spike-time dependent plasticity for after-effects of alpha-tACS were tested so far in simulations only (Zaehle et al., 2010). At the network level, responsiveness to acute SO-tDCS in rats appears to be affected after about 1 week of daily stimulation subsequent to learning on a spatial task (Binder et al., 2012). Although we can as yet not ascertain that learning or plastic changes in the cortical network occurred throughout the above experiment, the 
long-term implications of the study are that network "learning" can be induced and the dynamics and mechanisms of this process could in future be measured in detail.

Findings that the most consistent effect of SO-tDCS during SWS is on the endogenous sleep slow oscillatory rhythm implies that this oscillation of neocortical origin was primarily impacted by SO-tDCS, and causally affected memory consolidation and learning. But, selective activation and deactivation of other brain structures within the circuit, in combination with other methods, e.g., optogenetics, is furthermore required to highlight the specific function of the neocortical network for memory consolidation. Furthermore, the differential results of transcranial weak oscillatory stimulation due to brain state point out the necessity, as

\section{REFERENCES}

Akam, T. E., and Kullmann, D. M. (2012). Efficient "communication through coherence" requires oscillations structured to minimize interference between signals. PLoS Comput. Biol. 8:e1002760. doi: 10. 1371/journal.pcbi.1002760

Ali, M. M., Sellers, K. K., and Frohlich, F. (2013). Transcranial alternating current stimulation modulates large-scale cortical network activity by network resonance. $\mathrm{J}$. Neurosci. 33, 11262-11275. doi: 10. 1523/jneurosci.5867-12.2013

Antonenko, D., Diekelmann, S., Olsen, C., Born, J., and Mölle, M. (2013). Napping to renew learning capacity: enhanced encoding after stimulation of sleep slow oscillations. Eur. J. Neurosci. 37, 1142-1151. doi: 10. 1111/ejn.12118

Bechterew, V. (1900). Demonstration eines gehirns mit zerstörung der vorderen und inneren theile der hirnrinde beider schläfenlappen. Neurol. Centralbl. 19, 990-991.

Benchenane, K., Peyrache, A., Khamassi, M., Tierney, P. L., Gioanni, Y., Battaglia, F. P., et al. (2010). Coherent theta oscillations and reorganization of spike timing in the hippocampal- prefrontal network upon learning. Neuron 66, 921-936. doi: 10.1016/j.neuron. 2010.05.013

Benchenane, K., Tiesinga, P. H., and Battaglia, F. P. (2011). Oscillations in the prefrontal cortex: a gateway to memory and attention. Curr. Opin. Neurobiol. 21, 475-485. doi: 10. 1016/j.conb.2011.01.004

Binder, S., Rawohl, J., Born, J., and Marshall, L. (2012). Anodal slow oscillatory transcranial direct current stimulation (sotDCS) during sleep in rats: effects on radial maze performance and cortical activity. Poster Presented at the Federation of European Neuroscience (FENS) Meeting in Barcelona, Spain, July
14-18, http://fens.ekonnect.co/ FENS_331/poster_35655/program. aspx

Brown, S., and Schäfer, E. A. (1888). An investigation into he functions of the occipital and temporal lobes of the monkey's brain. Philos. Trans. $R$. Soc. Lond. B Biol. Sci. 179, 303-327. doi: 10.1098/rstb.1888.0011

Buhry, L., Azizi, A. H., and Cheng, S. (2011). Reactivation, replay, and preplay: how it might all fit together. Neural Plast. 2011:203462. doi: 10. 1155/2011/203462

Buser, P., and Rougeul-Buser, A. (1995). Do cortical and thalamic bioelectric oscillations have a functional role? A brief survey and discussion. J. Physiol. Paris 89, 249-254. doi: 10.1016/0928-4257 (96)83641-2

Buzsáki, G. (1989). Two-stage model of memory trace formation: a role for "noisy" brain states. Neuroscience 31, 551-570. doi: 10.1016/03064522(89)90423-5

Buzsáki, G., and Draguhn, A. (2004). Neuronal oscillations in cortical networks. Science 304, 1926-1929. doi: 10.1126/science. 1099745

Buzsáki, G., Haas, H. L., and Anderson, E. G. (1987). Long-term potentiation induced by physiologically relevant stimulus patterns. Brain Res. 435, 331-333. doi: 10.1016/00068993(87)91618-0

Campbell, I. G., and Feinberg, I. (2009). Longitudinal trajectories of nonrapid eye movement delta and theta EEG as indicators of adolescent brain maturation. Proc. Natl. Acad. Sci. U S A 106, 5177-5180. doi: 10. 1073/pnas.0812947106

Carracedo, L. M., Kjeldsen, H., Cunnington, L., Jenkins, A., Schofield, I., Cunningham, M. O., et al. (2013). A neocortical delta rhythm facilitates reciprocal interlaminar interactions via nested theta rhythms. J. Neurosci. 33, 10750-10760. doi: 10. 1523/jneurosci.0735-13.2013

technical capabilities develop, to consider this state-dependency in research approaches investigating local networks and neuronal properties, e.g., by mimicking different brain states in slice preparations. Finally, development and extension of computational network models can help guide systematic studies on transcranial weak oscillatory stimulation investigating coupled rhythms (e.g., Reato et al., 2013b).

\section{ACKNOWLEDGMENTS}

We thank Dominic Aumann for critiques of this manuscript. This work was supported by DFG (SFB 654, TP A6: Plasticity and Sleep) and German Ministry of Education and Research (BMBF, grant 01GQ1008).

Chrobak, J. J., and Buzsáki, G. (1996). High-frequency oscillations in the output networks of the hippocampal-entorhinal axis of the freely behaving rat. J. Neurosci. 16, 3056-3066.

Clemens, Z., Mölle, M., Eross, L., Jakus, R., Rasonyi, G., Halasz, P., et al. (2011). Fine-tuned coupling between human parahippocampal ripples and sleep spindles. Eur. J. Neurosci. 33, 511-520. doi: 10. 1111/j.1460-9568.2010.07505.x

Colgin, L. L. (2013). Mechanisms and functions of theta rhythms. Annu. Rev. Neurosci. 36, 295-312. doi: $\quad 10.1146 /$ annurev-neuro062012-170330

Csercsa, R., Dombovari, B., Fabo, D., Wittner, L., Eross, L., Entz, L., et al. (2010). Laminar analysis of slow wave activity in humans. Brain 133, 2814-2829. doi: 10.1093/brain/ awq169

Eggert, T., Dorn, H., Sauter, C., Nitsche, M. A., Bajbouj, M., and DankerHopfe, H. (2013). No effects of slow oscillatory transcranial direct current stimulation (tDCS) on sleep-dependent memory consolidation in healthy elderly subjects. Brain Stimul. doi: 10.1016/j.brs. 2013.05.006. [Epub ahead of print].

Fell, J., and Axmacher, N. (2011). The role of phase synchronization in memory processes. Nat. Rev. Neurosci. 12, 105-118. doi: 10.1038/ nrn2979

Fogel, S. M., and Smith, C. T. (2011). The function of the sleep spindle: a physiological index of intelligence and a mechanism for sleepdependent memory consolidation. Neurosci. Biobehav. Rev. 35, 1154 1165. doi: 10.1016/j.neubiorev.2010. 12.003

Fritsch, B., Reis, J., Martinowich, K., Schambra, H. M., Ji, Y., Cohen, L. G., et al. (2010). Direct current stimulation promotes BDNF-dependent synaptic plasticity: potential impli- cations for motor learning. Neuron 66, 198-204. doi: 10.1016/j.neuron. 2010.03.035

Fröhlich, F., and McCormick, D. A. (2010). Endogenous electric fields may guide neocortical network activity. Neuron 67, 129-143. doi: 10.1016/j.neuron.2010.06.005

Fujisawa, S., and Buzsáki, G. (2011). A $4 \mathrm{~Hz}$ oscillation adaptively synchronizes prefrontal, VTA, and hippocampal activities. Neuron 72 , 153-165. doi: 10.1016/j.neuron 2011.08.018

Giocomo, L. M., and Hasselmo, M. E. (2007). Neuromodulation by glutamate and acetylcholine can change circuit dynamics by regulating the relative influence of afferent input and excitatory feedback. $\mathrm{Mol}$. Neurobiol. 36, 184-200. doi: 10. 1007/s12035-007-0032-Z

Girardeau, G., and Zugaro, M. (2011). Hippocampal ripples and memory consolidation. Curr. Opin. Neurobiol. 21, 452-459. doi: 10.1016/j. conb.2011.02.005

Göder, R., Baier, P. C., Beith, B. Baecker, C., Seeck-Hirschner, M., Junghanns, K., et al. (2013). Effects of transcranial direct current stimulation during sleep on memory performance in patients with schizophrenia. Schizophr. Res. 144, 153-160. doi: 10.1016/j.schres.2012. 12.014

Groppa, S., Bergmann, T. O., Siems, C., Mölle, M., Marshall, L., and Siebner, H. R. (2010). Slow-oscillatory transcranial direct current stimulation can induce bidirectional shifts in motor cortical excitability in awake humans. Neuroscience 166, 12191225. doi: 10.1016/j.neuroscience. 2010.01.019

Herrmann, C. S., Rach, S., Neuling, T., and Struber, D. (2013). Transcranial alternating current stimulation: a review of the underlying mechanisms and modulation of cognitive processes. Front. Hum. 
Neurosci. 7:279. doi: 10.3389/ fnhum.2013.00279

Heys, J. G., and Hasselmo, M. E. (2012). Neuromodulation of $\mathrm{I}(\mathrm{h})$ in layer II medial entorhinal cortex stellate cells: a voltage-clamp study. $J$. Neurosci. 32, 9066-9072. doi: 10. 1523/jneurosci.0868-12.2012

Hirase, H., Leinekugel, X., Czurko, A., Csicsvari, J., and Buzsáki, G. (2001). Firing rates of hippocampal neurons are preserved during subsequent sleep episodes and modified by novel awake experience. Proc. Natl. Acad. Sci. U S A 98, 9386-9390. doi: 10.1073/pnas.161274398

Hutcheon, B., and Yarom, Y. (2000). Resonance, oscillation and the intrinsic frequency preferences of neurons. Trends Neurosci. 23, 216-222. doi: 10.1016/s01662236(00)01547-2

Hyman, J. M., Hasselmo, M. E., and Seamans, J. K. (2011). What is the functional relevance of prefrontal cortex entrainment to hippocampal theta rhythms? Front. Neurosci. 5:24. doi: 10.3389/fnins.2011.00024

Hyman, J. M., Zilli, E. A., Paley, A. M., and Hasselmo, M. E. (2005). Medial prefrontal cortex cells show dynamic modulation with the hippocampal theta rhythm dependent on behavior. Hippocampus 15, 739-749. doi: 10.1002/hipo. 20106

Hyman, J. M., Zilli, E. A., Paley, A. M., and Hasselmo, M. E. (2010). Working memory performance correlates with prefrontal-hippocampal theta interactions but not with prefrontal neuron firing rates. Front. Integr. Neurosci. 4:2. doi: 10.3389/neuro.07. 002.2010

Isomura, Y., Sirota, A., Ozen, S., Montgomery, S., Mizuseki, K., Henze, D. A., et al. (2006). Integration and segregation of activity in entorhinalhippocampal subregions by neocortical slow oscillations. Neuron 52, 871-882. doi: 10.1016/j.neuron. 2006.10.023

Jacobson, G. A., Diba, K., YaronJakoubovitch, A., Oz, Y., Koch, C., Segev, I., et al. (2005). Subthreshold voltage noise of rat neocortical pyramidal neurones. J. Physiol. 564, 145-160. doi: 10.1113/jphysiol. 2004.080903

Jacobs, J., Kahana, M. J., Ekstrom, A. D., and Fried, I. (2007). Brain oscillations control timing of single-neuron activity in humans. J. Neurosci. 27, 3839-3844. doi: 10. 1523/jneurosci.4636-06.2007

Jefferys, J. G. (1995). Nonsynaptic modulation of neuronal activity in the brain: electric currents and extracellular ions. Physiol. Rev. 75, 689-723.

Kim, J., Delcasso, S., and Lee, I. (2011). Neural correlates of object-inplace learning in hippocampus and prefrontal cortex. J. Neurosci. 31, 16991-17006. doi: 10. 1523/jneurosci.2859-11.2011

Kirov, R., Weiss, C., Siebner, H. R., Born, J., and Marshall, L. (2009). Slow oscillation electrical brain stimulation during waking promotes EEG theta activity and memory encoding. Proc. Natl. Acad. Sci. U S A 106, 15460-15465. doi: 10.1073/pnas.0904438106

Kopell, N., Kramer, M. A., Malerba, P., and Whittington, M. A. (2010). Are different rhythms good for different functions? Front. Hum. Neurosci. 4:187. doi: 10.3389/fnhum.2010.00187

Laktos, P., Shah, A. S., Knuth, K. H., Ulbert, I., Karmos, G., and Schroeder, C. E. (2005). An oscillatory hierarchy controlling neuronal excitability and stimulus processing in the auditory cortex. J. Neurophysiol. 94, 1904-1911. doi: 10.1152/jn. 00263.2005

Lee, A. K., and Wilson, M. A. (2002). Memory of sequential experience in the hippocampus during slow wave sleep. Neuron 36, 11831194. doi: $10.1016 / \mathrm{s} 0896-6273(02)$ 01096-6

Louie, K., and Wilson, M. A. (2001). Temporally structured replay of awake hippocampal ensemble activity during rapid eye movement sleep. Neuron 29, 145-156. doi: 10. 1016/s0896-6273(01)00186-6

Maris, E., van Vugt, M., and Kahana, M. (2011). Spatially distributed patterns of oscillatory coupling between high-frequency amplitudes and low-frequency phases in human iEEG. Neuroimage 54, 836-850. doi: $\quad 10.1016 /$ j.neuroimage.2010 09.029

Marr, D. (1970). A theory for cerebral neocortex. Proc. R. Soc. Lond. B Biol. Sci. 176, 161-234.

Marr, D. (1971). Simple memory: a theory for archicortex. Philos. Trans. $R$. Soc. Lond. B Biol. Sci. 262, 23-81. doi: 10.1098/rstb.1971.0078

Marshall, L., and Born, J. (2007). The contribution of sleep to hippocampus-dependent memory consolidation. Trends Cogn. Sci. 11, 442-450. doi: 10.1016/j.tics.2007. 09.001

Marshall, L., Helgadottir, H., Mölle, M., and Born, J. (2006). Boosting slow oscillations during sleep potentiates memory. Nature 444, 610 613. doi: $10.1038 /$ nature 05278
Marshall, L., Kirov, R., Brade, J., Molle, M., and Born, J. (2011). Transcranial electrical currents to probe EEG brain rhythms and memory consolidation during sleep in humans. PLoS One 6:e16905. doi: 10.1371/journal.pone.0016905

McCormick, D. A., Shu, Y.-S., and Hasenstaub, A. (2003). "Balanced recurrent excitation and inhibition in local cortical networks," in Excitatory-Inhibitory Balance: Synapses, Circuits, and Systems, eds T. K. Hensch and M. Fagioloni, (New York: Kluwer Academic/ Plenum Publishers), 113-124.

Merlet, I., Birot, G., Salvador, R., Molaee-Ardekani, B., Mekonnen, A., Soria-Frish, A., et al. (2013). From oscillatory transcranial current stimulation to scalp EEG changes: a biophysical and physiological modeling study. PLoS One 8:e57330. doi: 10.1371/journal. pone. 0057330

Mölle, M., Eschenko, O., Gais, S., Sara, S. J., and Born, J. (2009). The influence of learning on sleep slow oscillations and associated spindles and ripples in humans and rats. Eur. J. Neurosci. 29, 1071-1081. doi: $\quad 10.1111 /$ j.1460-9568.2009. 06654.x

Mölle, M., Yeshenko, O., Marshall, L., Sara, S. J., and Born, J. (2006). Hippocampal sharp wave-ripples linked to slow oscillations in rat slow-wave sleep. J. Neurophysiol. 96, 62-70. doi: 10.1152/jn.00014.2006

Morris, C. J., Aeschbach, D., and Scheer, F. A. (2012). Circadian system, sleep and endocrinology. Mol. Cell. Endocrinol. 349, 91-104. doi: 10.1016/j.mce.2011.09.003

Nadasdy, Z., Hirase, H., Czurko, A., Csicsvari, J., and Buzsáki, G. (1999). Replay and time compression of recurring spike sequences in the hippocampus. J. Neurosci. 19, $9497-$ 9507.

Neuling, T., Rach, S., and Herrmann, C. S. (2013). Orchestrating neuronal networks: sustained aftereffects of transcranial alternating current stimulation depend upon brain states. Front. Hum. Neurosci. 7:161. doi: 10.3389/fnhum. 2013.00161

Neuling, T., Rach, S., Wagner, S., Wolters, C. H., and Herrmann, C. S. (2012). Good vibrations: oscillatory phase shapes perception. $\mathrm{Neu}$ roimage 63, 771-778. doi: 10.1016/j. neuroimage.2012.07.024

O'Keefe, J., and Dostrovsky, J. (1971). The hippocampus as a spatial map. preliminary evidence from unit activity in the freely-moving rat.
Brain Res. 34, 171-175, doi: 10 1016/0006-8993(71)90358-1

O'Keefe, J., and Recce, M. L. (1993). Phase relationship between hippocampal place units and the EEG theta rhythm. Hippocampus 3, 317-330. doi: 10.1002/hipo. 450030307

Oudiette, D., and Paller, K. A. (2013). Upgrading the sleeping brain with targeted memory reactivation. Trends Cogn. Sci. 17, 142-149. doi: 10.1016/j.tics.2013.01.006

Ozen, S., Sirota, A., Belluscio, M. A., Anastassiou, C. A., Stark, E., Koch, C., et al. (2010). Transcranial electric stimulation entrains cortical neuronal populations in rats. $\mathrm{J}$. $\mathrm{Neu}$ rosci. 30, 11476-11485. doi: 10. 1523/jneurosci.5252-09.2010

Pavlides, C., and Winson, J. (1989). Influences of hippocampal place cell firing in the awake state on the activity of these cells during subsequent sleep episodes. J. Neurosci. 9, 2907 2918.

Penfield, W. (1974). Memory. autopsy findings and comments on the role of the hippocampus in experiential recall. Arch. Neurol. 31, 145-154. doi: 10.1001/archneur. 1974.00490390027001

Peyrache, A., Battaglia, F. P., and Destexhe, A. (2011). Inhibition recruitment in prefrontal cortex during sleep spindles and gating of hippocampal inputs. Proc. Natl. Acad. Sci. US A 108, 17207-17212. doi: 10. 1073/pnas.1103612108

Pogosyan, A., Gaynor, L. D., Eusebio, A., and Brown, P. (2009). Boosting cortical activity at beta-band frequencies slows movement in humans. Curr. Biol. 19, 1637-1641. doi: 10.1016/j.cub.2009.07.074

Rasch, B., Büchel, C., Gais, S., and Born, J. (2007). Odor cues during slow-wave sleep prompt declarative memory consolidation. Science 315 , 1426-1429. doi: 10.1126/science. 1138581

Reato, D., Rahman, A., Bikson, M., and Parra, L. C. (2013a). Effects of weak transcranial Alternating Current Stimulation on brain activity - a review of known mechanisms. Front. Hum. Neurosci. 7.

Reato, D., Gasca, F., Datta, A., Bikson, M., Marshall, L., and Parra, L. C. (2013b). Transcranial electrical stimulation accelerates human sleep homeostasis. PLoS Comput. Biol. 9:e1002898. doi: 10.1371/journal. pcbi. 1002898

Reato, D., Rahman, A., Bikson, M., and Parra, L. C. (2010). Low-intensity electrical stimulation affects network dynamics by modulating 
population rate and spike timing. J. Neurosci. 30, 15067-15079. doi: $\quad 10.1523 /$ jneurosci.2059-10. 2010

Richardson, M. J., Brunel, N., and Hakim, V. (2003). From subthreshold to firing-rate resonance. J. Neurophysiol. 89, 2538-2554. doi: 10. 1152/jn.00955.2002

Sadowski, J. H., Jones, M. W., and Mellor, J. R. (2011). Ripples make waves: binding structured activity and plasticity in hippocampal networks. Neural Plast. 2011:960389. doi: 10. 1155/2011/960389

Schmitt, L. I., Sims, R. E., Dale, N., and Haydon, P. G. (2012). Wakefulness affects synaptic and network activity by increasing extracellular astrocyte-derived adenosine. $J$. Neurosci. 32, 4417-4425. doi: 10. 1523/jneurosci.5689-11.2012

Scoville, W. B., and Milner, B. (1957). Loss of recent memory after bilateral hippocampal lesions. J. Neurol. Neurosurg. Psychiatry 20, 11-21. doi: 10.1093/neucas/2.4.259-af

Siapas, A. G., and Wilson, M. A. (1998). Coordinated interactions between hippocampal ripples and cortical spindles during slow-wave sleep. Neuron 21, 1123-1128. doi: 10. 1016/s0896-6273(00)80629-7

Sirota, A., Csicsvari, J., Buhl, D., and Buzsáki, G. (2003). Communication between neocortex and hippocampus during sleep in rodents. Proc. Natl. Acad. Sci. U S A
100, 2065-2069. doi: 10.1073/pnas. 0437938100

Skaggs, W. E., and McNaughton, B. L. (1996). Replay of neuronal firing sequences in rat hippocampus during sleep following spatial experience. Science 271, 1870 1873. doi: 10.1126/science.271.5257. 1870

Stagg, C. J., and Nitsche, M. A. (2011). Physiological basis of transcranial direct current stimulation. Neuroscientist 17, 37-53. doi: 10. 1177/1073858410386614

Strüber, D., Rach, S., TrautmannLengsfeld, S. A., Engel, A. K., and Herrmann, C. S. (2013). Antiphasic $40 \mathrm{~Hz}$ oscillatory current stimulation affects bistable motion perception. Brain Topogr. doi: 10 . 1007/s10548-013-0294-x. [Epub ahead of print].

Timofeev, I., and Steriade, M. (1996). Low-frequency rhythms in the thalamus of intact-cortex and decorticated cats. J. Neurophysiol. 76, 41524168.

Vigmond, E. J., Perez Velazquez, J. L., Valiante, T. A., Bardakjian, B. L., and Carlen, P. L. (1997). Mechanisms of electrical coupling between pyramidal cells. J. Neurophysiol. 78, 31073116.

Vittoz, N. M., and Berridge, C. W. (2006). Hypocretin/orexin selectively increases dopamine efflux within the prefrontal cortex: involvement of the ventral tegmental area. Neuropsychopharmacology
31, 384-395. doi: 10.1038/sj.npp. 1300807

Wallace, E., Benayoun, M., van Drongelen, W., and Cowan, J. D. (2011). Emergent oscillations in networks of stochastic spiking neurons. PLoS One 6:e14804. doi: 10.1371/journal. pone.0014804

Wang, X. J. (2010). Neurophysiological and computational principles of cortical rhythms in cognition. Physiol. Rev. 90, 1195-1268. doi: 10. 1152/physrev.00035.2008

Weiss, S. A., and Faber, D. S. (2010). Field effects in the CNS play functional roles. Front. Neural Circuits 4:15. doi: 10.3389/fncir.2010.00015

Wierzynski, C. M., Lubenov, E. V., Gu, M., and Siapas, A. G. (2009). State-dependent spike-timing relationships between hippocampal and prefrontal circuits during sleep. Neuron 61, 587-596. doi: 10.1016/j. neuron.2009.01.011

Wilson, M. A., and McNaughton, B. L. (1994). Reactivation of hippocampal ensemble memories during sleep. Science 265, 676-679. doi: 10.1126/science. 8036517

Yoshida, M., Giocomo, L. M., Boardman, I., and Hasselmo, M. E. (2011). Frequency of subthreshold oscillations at different membrane potential voltages in neurons at different anatomical positions on the dorsoventral axis in the rat medial entorhinal cortex. J. Neurosci. 31, 12683-12694. doi: 10. 1523/jneurosci.1654-11.2011
Zaehle, T., Rach, S., and Herrmann, C. S. (2010). Transcranial alternating current stimulation enhances individual alpha activity in human EEG. PLoS One 5:e13766. doi: 10. 1371/journal.pone.0013766

Conflict of Interest Statement: The authors declare that the research was conducted in the absence of any commercial or financial relationships that could be construed as a potential conflict of interest.

Received: 01 July 2013; accepted: 07 September 2013; published online: 26 September 2013.

Citation: Marshall L and Binder S (2013) Contribution of transcranial oscillatory stimulation to research on neural networks: an emphasis on hippocampo-neocortical rhythms. Front. Hum. Neurosci. 7:614. doi: 10.3389/ fnhum.2013.00614

This article was submitted to the journal Frontiers in Human Neuroscience.

Copyright () 2013 Marshall and Binder. This is an open-access article distributed under the terms of the Creative Commons Attribution License (CC BY). The use, distribution or reproduction in other forums is permitted, provided the original author(s) or licensor are credited and that the original publication in this journal is cited, in accordance with accepted academic practice. No use, distribution or reproduction is permitted which does not comply with these terms. 